\title{
SAND99-1940C
}

\section{THE GROWTH OF InAsSb/InAs/InPSb/InAs MID-INFRARED EMITTERS BY METAL-ORGANIC CHEMICAL VAPOR DEPOSITION}

R. M. Biefeld, J. D. Phillips, and S. R. Kurtz, Sandia National Laboratory, Albuquerque, NM, Albuquerque, NM 87185-0601

RECEIVED

ABSTRACT

DEC 2 ? 1999

We report on the metal-organic chemical vapor deposition (MOCVD) of strained layer OSTII superlattices (SLSs) of InAsSb/InAs/InPSb/InAs as well as mid-infrared optically pumped lasers grown using a high speed rotating disk reactor (RDR). The devices contain AlAsSb cladding layers and strained, type I, InAsSb/InAs/InPSb/InAs strained layer superlattice (SLS) active regions. By changing the layer thickness and composition of the SLS, we have prepared structures with low temperature $(<20 \mathrm{~K})$ photoluminescence wavelengths ranging from 3.4 to 4.8 $\mu \mathrm{m}$. The optical properties of the InAsSb/InPSb superlattices revealed an anomalous low energy transition that can be assigned to an antimony-rich, interfacial layer in the superlattice. This low energy transition can be eliminated by introducing a $1.0 \mathrm{~nm}$ InAs layer between the InAsSb and InPSb layers in the superlattice. An InAsSb/InAs/InPSb/InAs SLS laser was grown on an InAs substrate with $\mathrm{AlAs}_{0.16} \mathrm{Sb}_{0.84}$ cladding layers. A lasing threshold and spectrally narrowed laser emission were seen from 80 through $250 \mathrm{~K}$, the maximum temperature where lasing occurred. The temperature dependence of the SLS laser threshold is described by a characteristic temperature, $\mathrm{T}_{0}=39 \mathrm{~K}$, from 80 to $200 \mathrm{~K}$.

\section{INTRODUCTION}

We are exploring the growth of novel mid-infrared (3-5 $\mu \mathrm{m})$ emitters (lasers and LED's) by metal-organic chemical vapor deposition (MOCVD) for use in infrared countermeasures and chemical sensor systems. Previously we have made gain-guided, injection lasers using not intentionally doped, p-type $\mathrm{AlAs}_{0.16} \mathrm{Sb}_{0.84}$ for optical confinement and both strained InAsSb/InAs multiple quantum well (MQW) and InAsSb/InAsP strained-layer superlattice (SLS) active regions $[1,2]$. We have also reported the first ten-stage cascaded lasers and LED's with type I InAsSb/InAsP quantum-well active regions grown by MOCVD [3]. These cascaded lasers employ a (p) GaAsSb/ (n) InAs semimetal electron/hole source between stages. In compressively strained InAsSb SLSs, it is necessary to maximize the light-heavy $(13 / 2, \pm 1 / 2>-13 / 2, \pm 3 / 2>)$ hole splitting to suppress non-radiative Auger recombination. Recently, Bewley et al. have reported record high output powers and operating temperatures for mid-infrared InAs/GaInSb/AlAsSb type II optically pumped lasers using a diamond-pressure-bond heat sinking technique [4]. We are currently exploring the growth of new emitter structures as well as the use of novel materials in these structures to improve our laser performance. In an attempt to further reduce the Auger recombination by increasing the hole confinement, we have used InPSb in place of InAsP as the barrier layer in the active region. We have reported an initial study on the synthesis and properties of these InAsSb/InPSb SLSs grown by MOCVD [5]. In this previous work we reported on the presence of an anomalous low energy transition that can be assigned to an antimony rich interfacial layer. This paper further explores the properties of these novel superlattices including the elimination of the anomalous transition and improvement of the photoluminescence and lasing properties through the addition of an InAs interfacial layer. 


\section{DISCLAIMER}

This report was prepared as an account of work sponsored by an agency of the United States Government. Neither the United States Government nor any agency thereof, nor any of their employees, make any warranty, express or implied, or assumes any legal liability or responsibility for the accuracy, completeness, or usefulness of any information, apparatus, product, or process disclosed, or represents that its use would not infringe privately owned rights. Reference herein to any specific commercial product, process, or service by trade name, trademark, manufacturer, or otherwise does not necessarily constitute or imply its endorsement, recommendation, or favoring by the United States Government or any agency thereof. The views and opinions of authors expressed herein do not necessarily state or reflect those of the United States Government or any agency thereof. 


\section{DISCLAIMER}

Portions of this document may be illegible in electronic image products. Images are produced from the best available original document. 
The InAsSb/InPSb and InAsSb/InAs/InPSb/InAs SLSs were grown by MOCVD on undoped n-type InAs substrates. We optimized the growth of these structures by first investigating the growth of InAsSb/InAs and InPSb/InAs SLSs. We investigated the InAsSb/InPSb SLS growth using different purge times (1,3, and 5) seconds with and without arsine flowing during the purge between InAs and the ternary layer growth. This was done to determine the effect of an arsine purge on the quality of the photoluminescence for the SLSs. A low V/III ratio is necessary for the growth of high quality InAsSb. Due to the low vapor pressure of $\mathrm{Sb}$, excess $\mathrm{Sb}$ tends to cause surface morphology defects. For InPSb, the V/III ratio is dominated by the excess phosphine flow. A high V/III ratio and excess phosphine flow are necessary because of the high decomposition temperature of phosphine. In both cases, InAsSb/InAs and InPSb/InAs, the composition dependence was reproducible and approximately linear versus $\mathrm{AsH}_{3}$ flow for InAsSb and TESb flow for InPSb for the composition range that was examined.

The SLSs were grown at 500 or $550^{\circ} \mathrm{C}$ and 70 torr in an Emcore D75 high speed rotating disk reactor at $1100 \mathrm{rpm}$. The sources used were trimethylindium (TMIn), triethylantimony (TESb), $100 \%$ or $10 \% \mathrm{AsH}_{3}$ in hydrogen, and $100 \% \mathrm{PH}_{3}$. The carrier gas and its quantity were 15 liters of hydrogen. The SLS composition and strain were determined by double crystal x-ray diffraction (DCXRD).

Infrared photoluminescence (PL) was measured on all samples from $16 \mathrm{~K}$ up to $300 \mathrm{~K}$ using a double-modulation, Fourier-transform infrared (FTIR) technique which provides high sensitivity, reduces sample heating, and eliminates the blackbody background from infrared emission spectra. The laser output characteristics were also measured using double modulation FTIR.

\section{RESULTS AND DISCUSSION}

The InAsSb layers were grown using a V/III ratio of 7.5 to 15 and an $\mathrm{AsH}_{3} /\left(\mathrm{AsH}_{3}+\mathrm{TESb}\right)$ ratio of 0.69 to 0.88 for compositions between 0.1 and $0.25 \mathrm{Sb}$ in InAsSb at a growth rate between 2.5 to $5 \AA$ /second. For the laser structures, a 1 second purge, with all reactants except for $\mathrm{AsH}_{3}$ switched out of the chamber, was used between each layer. This was the procedure that had been used previously for the growth of InAsSb/InAsP laser structures [2]. For both In $\mathrm{AsSb}$ and InPSb the growth rate was found to be proportional to the TMIn flow into the reaction chamber and independent of the TESb and $\mathrm{AsH}_{3}$ flow. The InPSb layers, whose growth has been described in more detail previously [5,6], were grown using a V/III ratio between 400 to 900 and a TESb/(TESb $+\mathrm{PH}_{3}$ ) ratio of 0.004 to 0.002 with growth rates of 2.5 to $5 \AA$ /second for compositions between 0.8 and $0.7 \mathrm{P}$ in InPSb. If the $\mathrm{TESb} /\left(\mathrm{TESb}+\mathrm{PH}_{3}\right)$ ratio was decreased below 0.002 , poor quality superlattices resulted. The SLS composition and strain were determined by double crystal x-ray diffraction. The crystal quality of the SLSs was excellent with 4 to 5 orders of $x$-ray diffraction satellite peaks typically observed, with typical full width at half maximum linewidths of 80-100 arc seconds. The Sb composition could be varied between 0.13 to 0.24 while maintaining constant layer thickness for both the InAsSb and InPSb layers.

For a change of composition in In $\mathrm{As}_{1-\mathrm{x}} \mathrm{Sb}_{\mathrm{x}}$, for $\mathrm{x}=0.14$ to 0.20 , with $\operatorname{InP}_{0.72-0.75} \mathrm{Sb}_{0.28-0.25}$ barriers, the PL peak changes from 3.5 to $4.2 \mu \mathrm{m}$ at $16 \mathrm{~K}$ and a corresponding shift to longer wavelengths is observed at room temperature. Photoluminescence linewidths (full width at half maximum) of $\sim 15 \mathrm{meV}$ and $\sim 35 \mathrm{meV}$ are typically observed at $16 \mathrm{~K}$ and room temperature, 

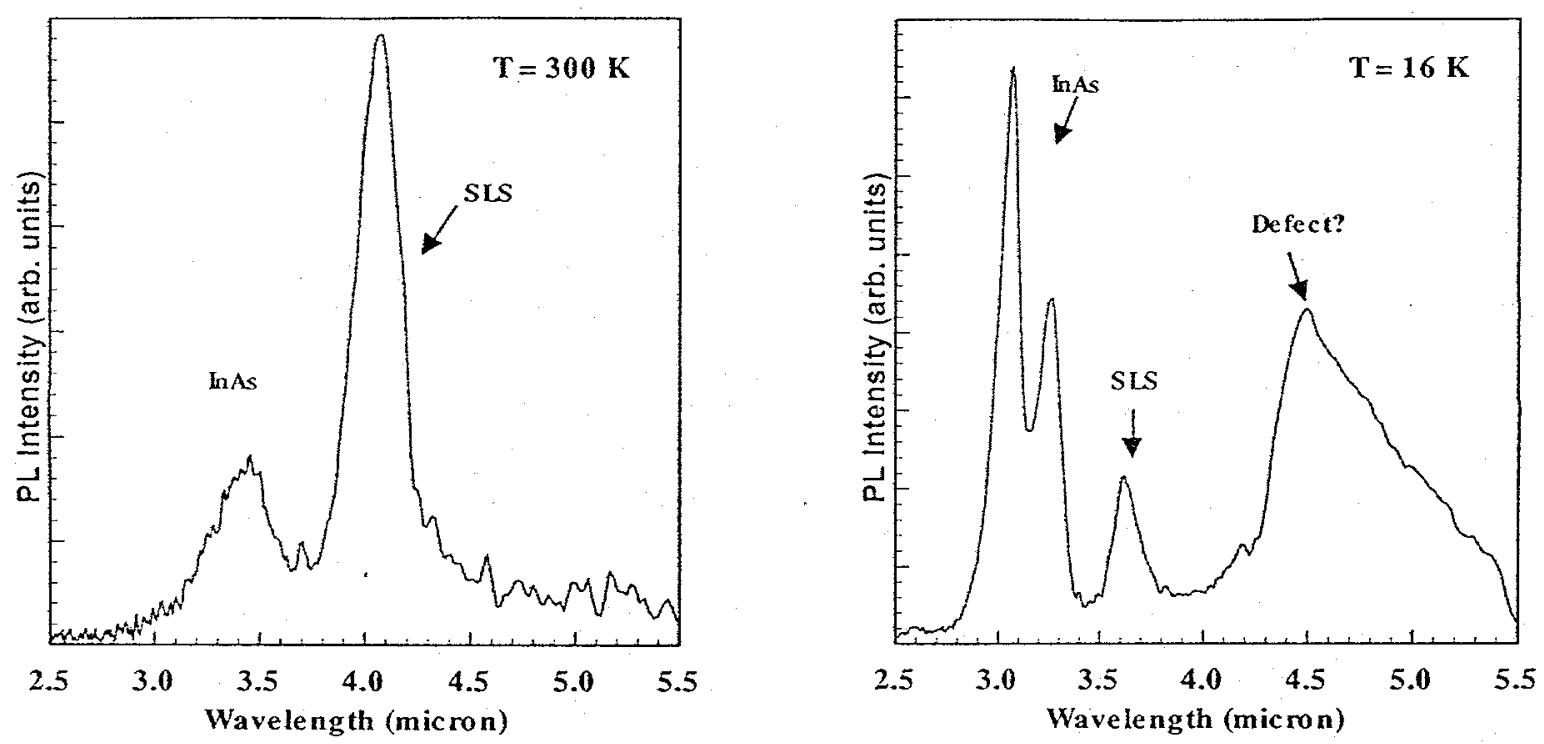

Figure 1. The 300 and $16 \mathrm{~K} \mathrm{PL}$ spectra of an $\operatorname{InAs_{0.84}} \mathrm{Sb}_{0.15} / \mathrm{InP}_{0.75} \mathrm{Sb}_{0.25} 10$ period SLS grown at $500^{\circ} \mathrm{C}$.

respectively, with no observable dependence on antimony composition. A decrease in the PL peak intensity by an order of magnitude is observed for samples with In $A s_{1-x} S_{x}, x<0.16$, likely due to decreased carrier confinement. By changing the layer thickness and composition of InAsSb/InPSb SLSs, we have prepared structures with low temperature $(<20 \mathrm{~K})$ photoluminescence wavelengths ranging from 3.4 to $4.8 \mu \mathrm{m}$.

We have observed a long wavelength emission in the photoluminescence that was not attributable to InAsSb. Figure 1 shows the 16 and $300 \mathrm{~K} \mathrm{PL}$ spectra of an InAs $\mathrm{s}_{0.84} \mathrm{Sb}_{0.15} /$ $\mathrm{InP}_{0.75} \mathrm{Sb}_{0.25} 10$ period SLS grown at $500{ }^{\circ} \mathrm{C}$. Peaks from the InAs substrate $(3.0$ and $3.25 \mu \mathrm{m})$, the InAsSb layer $(3.65 \mu \mathrm{m})$ and a longer emission at $4.5 \mu \mathrm{m}$ are observed in the $16 \mathrm{~K}$ spectrum; however, at $300 \mathrm{~K}$ the long wavelength peak disappears. This anomalous long wavelength peak could be reduced by growing at $550^{\circ} \mathrm{C}$ and by increasing the Sb content of the InAsSb layer.

Figure 2 illustrates the PL peaks that are observed for an InAs / InP $\mathrm{P}_{0.75} \mathrm{Sb}_{0.25} 10$ period SLS. The PL peaks at 3.0 and 3.3 are due to InAs. We would expect only the PL peaks from InAs and the shorter wavelength emission from InPSb, but we again observed the anomalous long wavelength peak near $5 \mu \mathrm{m}$. As illustrated in Figure 2, we have found that this anomalous peak can be effectively eliminated by increasing the $\mathrm{AsH}_{3}$ exposure of the InPSb/InAs interfaces. Figure 2 shows the PL spectra from three InPSb/InAs SLSs grown with different exposure levels of $\mathrm{AsH}_{3}$ ranging from a 1 second purge in which no $\mathrm{AsH}_{3}$ was used in Figure 2a to 3 and 5 second purges with $\mathrm{AsH}_{3}$ flowing during the purges shown in Figures $2 \mathrm{~b}$ and $\mathrm{c}$, respectively. From this result we conclude that the anomalous long wavelength PL peak is due to an antimony-rich, interfacial layer that can be minimized by changing the growth conditions at the interface.

As previously reported, we have successfully prepared optically pumped laser structures from these InAsSb/InPSb SLS active regions [5]. However, the performance of these lasers was not as good as our InAsSb/InAsP lasers [2,3]. To improve this performance we have explored the growth of InAsSb/InAs/InPSb/InAs SLSs to be used as active regions in optically pumped lasers. Figure 3 shows the PL results for three 10 period superlattice structures with $1.0 \mathrm{~nm}$ InAs layers grown at (a) both interfaces, (b) after the InPSb and before the InAsSb layer, and (c) after the InAsSb layer and before the InPSb layer. The most intense PL was observed for the sample in (a) with InAs layers at both interfaces. The greatest effect was observed when the InAs layer was placed after the InPSb layer and before the InAsSb layer. A long wavelength, low intensity PL 


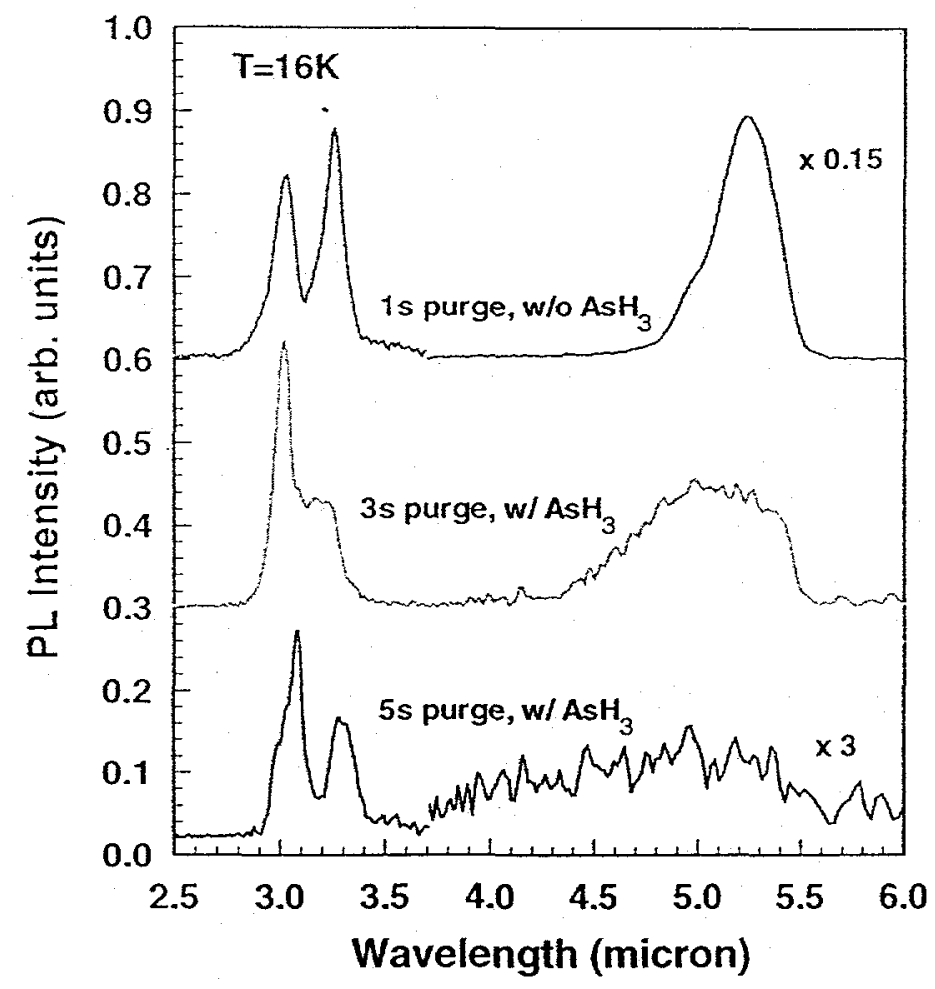

Figure 2. The PL spectra from three InPSb/InAs SLSs grown with different exposure levels of $\mathrm{AsH}_{3}$ ranging from (a) 1 second purge in which no $\mathrm{AsH}_{3}$ was used,to 3 and 5 second purges with $\mathrm{AsH}_{3}$ flowing during the purges shown in Figures (b) and (c), respectively.

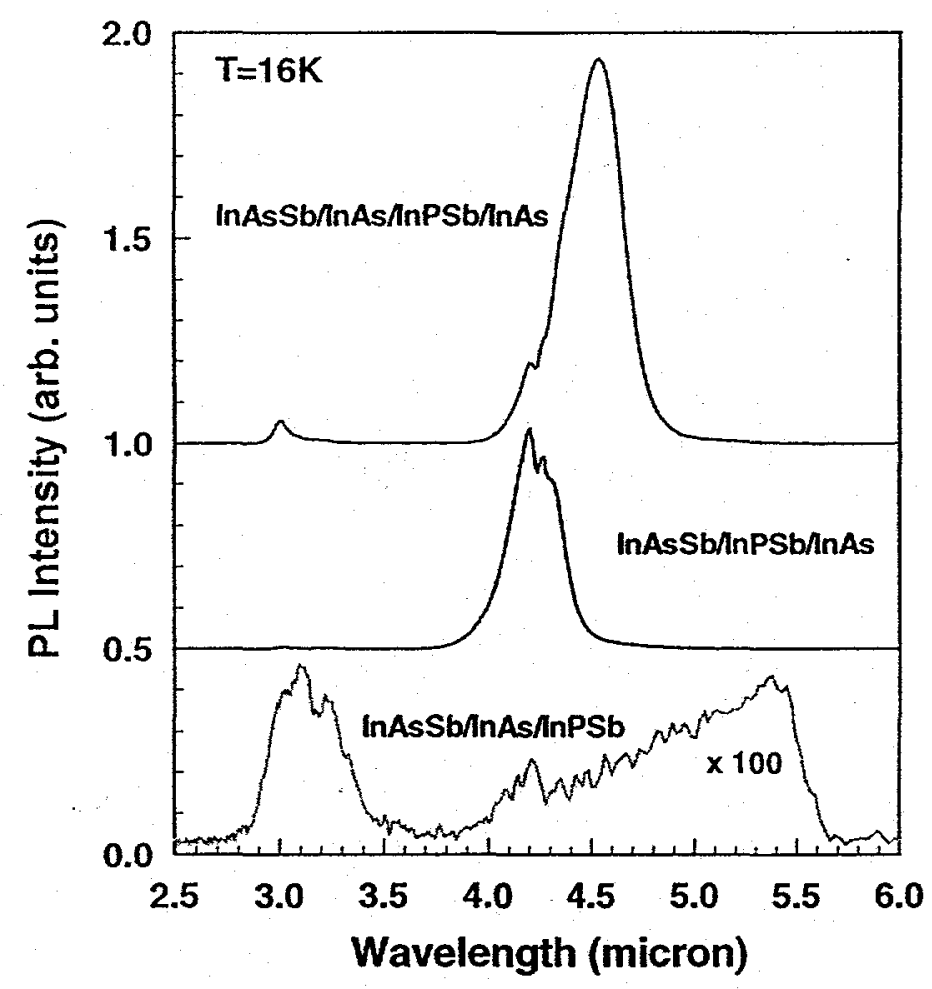

Figure 3. The PL spectra from (a) an InAsSb/InAs/InPSb/InAs SLS, (b) an InAsSb/InPSb/InAs $\mathrm{SLS}$, and (c) an InAsSb/InAs/InPSb SLS. 

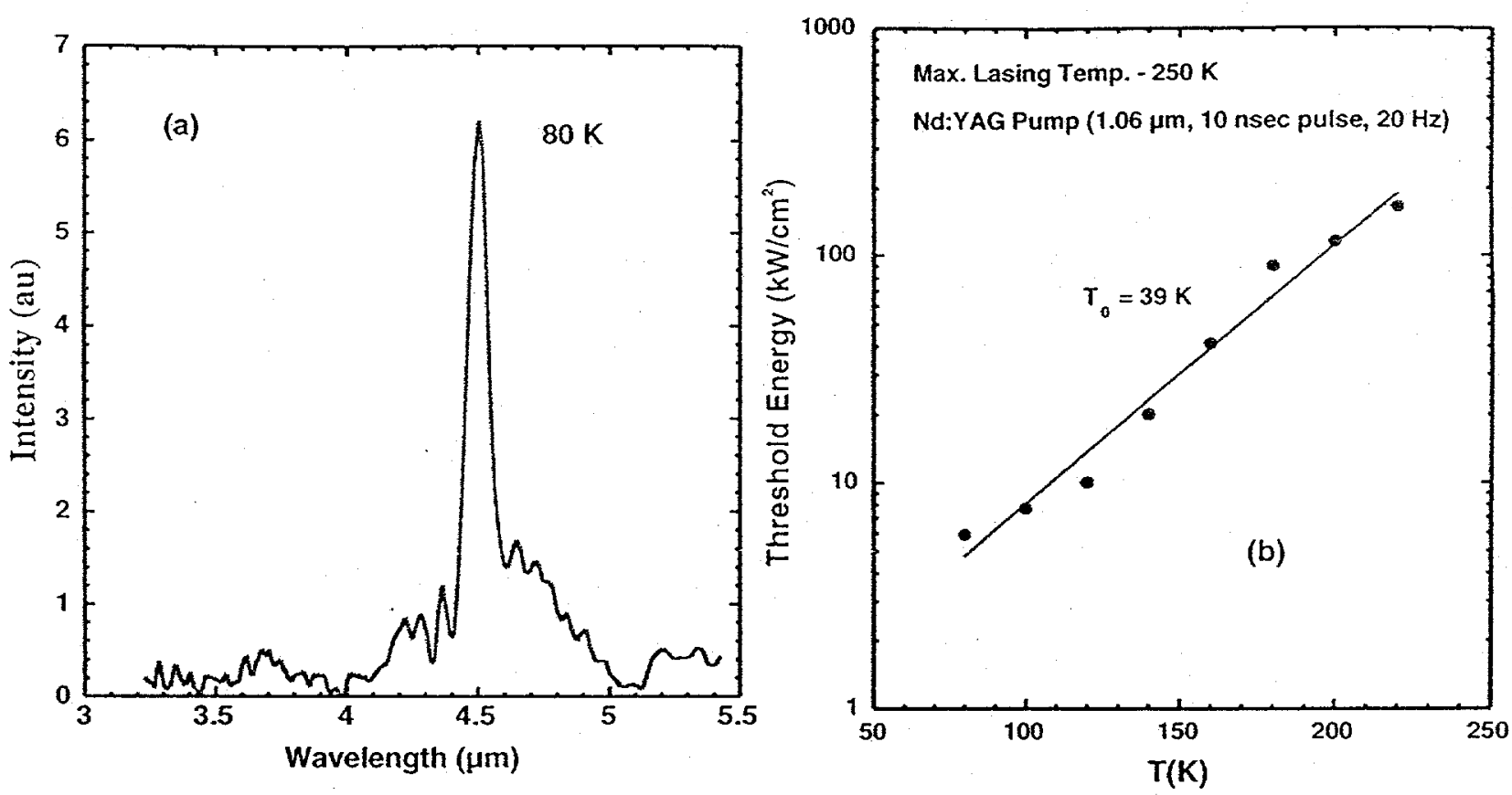

Figure 4. (a) Emission spectra at $80 \mathrm{~K}$ for a ten well, InAsSb/InAs/InPSb/InAs optically pumped laser structure. (b) The temperature dependence of the threshold current for the laser in (a)

peak (c), which can not be assigned to the InAsSb layer, was observed when the InAs layer was grown after the InAsSb layer. The intensity of the four layer, 10 period SLS shown in Figure 3(a) was an order of magnitude larger than the intensities observed for InAsSb/InPSb SLSs . where no InAs interfacial layers were used. These results again illustrate how important the interfaces are in controlling the quality of the PL of the InAsSb/InPSb SLSs.

An optically pumped heterostructure laser was grown on an InAs substrate with a $2 \mu \mathrm{m}$ thick $\mathrm{AlAs}_{0.16} \mathrm{Sb}_{0.84}$ lower cladding followed by a $0.5 \mu \mathrm{m}$ InAs spacer. On top of the InAs spacer, the active region consisted of a 10 period, InAs $0.82 \mathrm{Sb}_{0.18} / \mathrm{InAs} / \mathrm{InP}_{0.73} \mathrm{Sb}_{0.27} / \mathrm{InAs}(104 \AA / 10 \AA$ $104 \AA / 10 \AA$ ) SLS. The structure was then completed with another $0.5 \mu \mathrm{m}$ of InAs and a $1.0 \mu \mathrm{m}$ top $\mathrm{AlAs}_{0.16} \mathrm{Sb}_{0.84}$ cladding layer. The $\mathrm{AlAs}_{0.16} \mathrm{Sb}_{0.84}$ cladding layer was covered with a $40 \mathrm{~nm}$ InAs cap layer to avoid oxidation. Laser devices were fabricated by cleaving the grown heterostructures into $1 \times 5 \mathrm{~mm}$ bars, with uncoated facets, and mounting them on a copper heat sink using In solder. The SLS laser was pumped with a Q-switched Nd:YAG laser $(1.06 \mu \mathrm{m}, 20$ $\mathrm{Hz}, 10 \mathrm{nsec}$ pulse, focused to a $200 \mu \mathrm{m}$ wide line), and emission was detected with an FTIR spectrometer operated in a step-scan mode. A lasing threshold and spectrally narrowed, laser emission were seen from 80 (see Figure $4 \mathrm{a}$ ) through $250 \mathrm{~K}$, the maximum temperature where lasing occurred. The photoluminescence peak energy for this structure shifted from 4.7 to 5.4 $\mu \mathrm{m}$ over a temperature range of 16 to $300 \mathrm{~K}$. The temperature dependence of the SLS laser threshold is described by a characteristic temperature, $\mathrm{T}_{0}=39 \mathrm{~K}$, from 80 to $200 \mathrm{~K}$ (see Figure 4b). This value is higher than observed in our previous lasers [1-3], and suggests that the use of InPSb barriers will lead to increased operating temperatures compared to the lasers with InAsP. barriers. This higher characteristic temperature is similar to those observed in the current state of the art InAs/GaInSb/AlAsSb type II optically pumped lasers [4]. Estimated peak powers of about $300-10 \mathrm{~mW} /$ facet and thresholds of $6-170 \mathrm{~kW} / \mathrm{cm}^{2}$ are similar to those observed for the previously reported InAsSb/InAsP SLS lasers [2]. 
In summary, we have successfully prepared InAsSb/InPSb SLSs by MOCVD. We observed an anomalous long wavelength emission which we have assigned to an interface state by examining the PL of InAs/InPSb SLSs. We have completely eliminated this anomalous emission by inserting an InAs layer at both of the InAsSb/InPSb interfaces. We have prepared optically pumped laser structures using InAsSb/nnAs/InPSb/InAs SLSs as the active regions and observed a $\mathrm{T}_{0}=39 \mathrm{~K}$ for these type I InAsSb SLS lasers. With further improvement in growth conditions optimization of the interface transition, and laser design, the high $\mathrm{T}_{0}$ we have observed leads us to believe that higher performance lasers are possible with these InAsSb/InAs/InPSb/InAs SLSs.

\section{ACKNOWLEDGEMENTS}

*This work was supported by the US DOE under Contract No. DE-AC04-94AL85000. Sandia is a multiprogram laboratory operated by Sandia Corporation, a Lockheed Martin Company, for the United States Department of Energy.

\section{REFERENCES}

[1] A. A. Allerman, R. M. Biefeld, and S. R.Kurtz, "InAsSb-based mid-infrared lasers (3.8-3.9 $\mu \mathrm{m})$ and light-emitting diodes with AIAsSb claddings and semi-metal electron injection grown by metal-organic chemical vapor deposition," Appl. Phys. Lett. 69, pp. 465-467, 1996.

[2] S. R. Kurtz, A. A. Allerman, and R. M. Biefeld "Mid-infrared lasers and light-emitting diodes with InAsSb/InAsP strained-layer superlattice active regions" Appl. Phys. Lett. 70, pp. 3188-3190, 1997.

[3] S. R. Kurtz, A. A. Allerman, R. M. Biefeld and K. C. Baucom, "High slope efficiency, "cascaded" midinfrared lasers with type I InAsSb quantum wells" Appl. Phys. Lett. 72, pp. 2093-2095, 1998.

[4] W. W. Bewley, C. L. Felix, I. Vurgaftman, D. W. Stokes, E. H. Aifer, L. J. Olafsen, J. R. Meyer, M. J. Yang, B. V. Shanabrook, H. Lee, R. U. Martinelli, and A. R. Sugg "Hightemperature continuous-wave 3-6.1 m "W" lasers with diamond-pressure-bond heat sinking" Appl. Phys. Lett. 74, 1075 (1999).

[5] R. M. Biefeld, J. D. Phillips, and S. R. Kurtz, J. Electron. Mater., to be published Jan, 2000.

[6] R. M. Biefeld, K. C. Baucom, S. R. Kurtz, and D. M. Follstaedt, "The growth of $\operatorname{InP}_{1-\mathrm{x}} \mathrm{Sb}_{\mathrm{x}}$ by metalorganic chemical vapor deposition", J. Crystal Growth 133, 38 (1993). 